\title{
Spread of the COVID-19 in Russia: Regional Peculiarities
}

\author{
N. A. Kravchenko ${ }^{a, b}, *$ and A. I. Ivanova ${ }^{a, b}, * *$ \\ ${ }^{a}$ Institute of Economics and Industrial Engineering, Siberian Branch, Russian Academy of Sciences, \\ Novosibirsk, 630090 Russia \\ ${ }^{b}$ Novosibirsk National Research State University, Novosibirsk, 630090 Russia \\ *e-mail: natakravchenko20@mail.ru \\ **e-mail: a.ivanova2@g.nsu.ru
}

Received April 18, 2021; revised April 18, 2021; accepted July 16, 2021

\begin{abstract}
The spread of COVID-19 is highly differentiated both between countries and between territories within countries. The main aim of this article is to identify the characteristics of regions that affect the scale of spread of coronavirus infection in the Russian Federation during the second wave of the pandemic. Using econometric modeling methods, the dependences between a number of regional characteristics reflecting the vulnerability of regions and their ability to resist infection were assessed, in addition to the scale of the spread of coronavirus infection. The wealth of a region and social capital of its population became the factors of resistance. The populations of wealthier Russian regions are less exposed to infection, while the most vulnerable are poorer regions, regions with a high population density, poorer environmental quality, and older populations. The article demonstrates the role of social capital in resisting a pandemic: higher quality social capital is associated with lower infection and mortality rates. The findings can be used to inform regional policy measures to potentially reduce COVID-19 and other infections.
\end{abstract}

Keywords: COVID-19 pandemic, Russian regions, vulnerability and resistance factors, social capital

DOI: $10.1134 / \mathrm{S} 2079970521040080$

\section{REGIONAL DIFFERENTIATION OF THE SPREAD OF THE COVID-19 PANDEMIC}

For more than a year, people in most countries have been living in a "new reality" forming as a result of the spread of coronavirus infection and the fight against the pandemic. It differs from earlier pandemics in its global scale, rate of spread, information transparency, and interactions in countering it.

The first wave of the COVID-19 pandemic spread around the world in a situation of unmanageable uncertainty. Currently, uncertainty remains in spite of the significant advances not only in understanding the mechanisms behind the spread of infection, but also in the development of drugs and preventive methods (vaccines) and treatment. The incidence rate continues to rise. There is a danger of further escalation of morbidity. A significant amount of empirical material and research has already been accumulated, which shows that in different countries, the dynamics and scale of spread and impact of the pandemic on society and economies differ. Within countries, regional differentiation is even greater.
As of November $2020^{1}$ in China, $83 \%$ of confirmed COVID-19 cases were detected in Hubei Province; in Italy, the region of Lombardy was most affected (47\% of cases); in France, the Ile-de-France region (34\%); in the United States, New York (14.6\%); in Brazil, São Paulo (25\%).

As of April 2021, Russia ranked fifth in the world in the number of COVID-19 cases (after the United States, Brazil, India, and France) and seventh in terms of the number of deaths (after the United States, Brazil, Mexico, India, Italy, Great Britain). ${ }^{2}$ As of April 3, 2021 (authors' calculations), the share of Moscow in the total number of infected people was $23 \%$. The three Russian regions with the highest number of infected (Moscow, St. Petersburg, and Moscow Oblast) account for $36 \%$ of all COVID-19 cases, and top ten Russian regions with the highest number of infections account for almost half. The proportion of

\footnotetext{
${ }^{1}$ OECD Policy Responses to Coronavirus (COVID-19). The territorial impact of COVID-19: Managing the crisis across levels of government. Updated November 10, 2020. http://www.oecd.org/coronavirus/policy-responses/the-territorial-impact-of-covid-19-managing-the-crisis-across-levelsof-gavernment-d3e314e1/. Accessed April 10, 2021.

${ }^{2}$ Data from Johns Hopkins University (Coronavirus Resource Center). https://coronavirus.jhu.edu/map.html.
} 
people infected with coronavirus with respect to the population in Moscow is 16 times higher than that in the Republic of Tatarstan.

The wavelike onset of the coronavirus and associated factors differ, according to the data of the first and second (in Russia since mid-September 2020) waves. Whereas the spread of infection in the first wave was associated with unpredictable random factors, after a year of life in a pandemic, it can be suggested that a more stable relationship between the scale of infection and the characteristics of different Russian regions has already appeared.

The main aim of this article is to identify the characteristics of regions that affect the scale of spread of COVID-19 in the Russian Federation.

\section{STATE OF RESEARCH: WHAT REGIONAL FEATURES INFLUENCE INFECTION?}

The asymmetric impact of the spread of COVID-19 and its consequences between countries and regions within countries ${ }^{3}$ is associated with many factors of various nature, each contributing to the stochastic process. Complex nonlinear relationships create a special situation for each location. The origins of the spatial asymmetry of regional development are diverse, associated with factors of both the first (geography and climate) and second (population density and concentration of economic activity) type (Bailey et al., 2020; Kolomak, 2013). In a pandemic, factors that have had clear benefits in the past (such as agglomeration effects and density of interactions) can contribute to the spread of COVID-19 and its consequences.

Different regional characteristics are significant for different stages of the spread of a pandemic. The hardest hit regions in the first wave were major metropolitan areas such as New York and London, with vibrant social life, diverse populations, and densely populated residential areas. In second place in terms of the spread of infection were large industrial centers connected by global supply chains (Azzolina et al., 2020).

The first wave of the pandemic in Russia (MarchMay 2020) mostly affected the largest agglomerations with a high population density and high level of contacts: international centers of transport, commodity and financial flows, and border and coastal regions, with a predominance of random factors (Kalabikhina and Panin, 2020; Zemtsov and Baburin, 2020a). An OECD report and an article by Russian researchers (Puzanov and Alov, 2020) emphasize that a direct relationship between population density and morbidity has not been established. The incidence rate with respect to the population of a region in the first wave of the pandemic was higher not in the most populated regions, but in smaller populated areas, where out-

\footnotetext{
${ }^{3}$ Significant differentiation is also observed in areas within cities, in particular, Moscow (Puzanov and Alov, 2020).
}

breaks of infections associated with "supercarriers" occurred (Bailey et al, 2020), which indicates the strong influence of nonsystemic (random) factors on the epidemiological situation. Perhaps the most famous example is a conference in Boston (United States) in February 2020, which brought together leaders in biotechnology from around the world: 90 people were infected, ${ }^{4}$ who then dispersed to cities and countries.

The second wave began in September 2020, and we believe that the dynamics and scale of infection were influenced by more fundamental characteristics of the regions, which is confirmed by the stable ranking (preservation of order) of the most affected regions.

For this study, we divided the numerous features of the regions that can affect the spread of coronavirus into two groups of characteristics: (1) those that reflect the vulnerability of the region to the spread of infection and (2) those that develop the ability to resist the spread of the disease.

A region's vulnerability to the spread of infection depends on a wide range of factors: climatic (in warmer and drier regions, spreading is less), geographic, demographic, economic, social, political (in the United States, red states with Republican leadership introduced less stringent restrictions and experienced a greater increase in morbidity than blue states (Hallas et al., 2021)) and others, which directly or indirectly affect the incidence of coronavirus infection.

Resistance to the spread of a new, unknown infection transmitted by contact in the absence of specific vaccines and medicines depends on the speed and rigidity of implemented measures to limit mobility and contacts between people (closing of external borders, borders between regions within countries, stopping business activity, introduction of quarantine measures, social distancing, etc.). Restrictions on economic and social contacts and their observance have been and remain the main nonpharmaceutical actions aimed at inhibiting infection processes.

We have focused on several regional characteristics associated with the spread of the coronavirus, as demonstrated by the research results.

Wealth of regions. The indicator of gross income per capita is conventionally used in regional studies. The relationship between gross income per capita and infection and mortality rates can be both negative and positive. Regions with high GRP per capita are more urbanized, embedded in global trade and transport flows, large companies are located in them, and they are characterized by a rich social life. As a result of the concentration of economic and social activity in wealthy regions, higher infection and mortality rates can be expected. This assumption is confirmed, e.g., by the results of (Kapitsinis, 2020) across 119 regions

\footnotetext{
${ }^{4}$ According to recent data based on decoding of the genome, the infection spread to 20000 people.
} 
in 9 European Union countries: wealthier regions have higher infection and mortality rates. However, wealthy regions have not only a dense network of contacts, but also more developed infrastructure and healthcare systems, and there are also more opportunities for telecommuting.

At the same time, in poor regions, many people cannot stop economic activity due to low income; in addition, they have fewer opportunities to work remotely due to the nature of work or lack of access to appropriate infrastructure. In such regions, provision of health services is also lower. Woods (2020) argues the existence of a feedback loop between the wealth of the region and the prevalence of infection: both COVID-19 and measures taken to control its spread predominantly affect poor strata and impoverished districts. Factors that contribute to higher mortality in poor areas include a high prevalence of chronic diseases, limited access to health services, and demographic and occupational characteristics.

Population density. Among the factors contributing to the spread of infection, researchers consider the population density and size, including the presence of large urban agglomerations in a region. However, the results obtained are ambiguous.

Large cities are characterized by a high density of businesses, a developed communications network, including public transport, the presence of large shops and other places where people concentrate, which makes it possible to consider COVID-19 a megalopolitan pandemic. Conversely, rural areas have suffered the least (Woods, 2020).

Yu. Ponomarev and D. Radchenko (2020) confirm that the populations of million-plus cities are most at risk of contracting coronavirus. S.P. Zemtsov and V.L. Baburin $(2020 \mathrm{a}, 2020 \mathrm{~b})$ hew to a similar viewpoint, noting that regions with a high proportion of urban population are most susceptible to the spread of a pandemic, since in cities not only is the sanitation intensity higher, but natural and ecological conditions also deteriorate, which negatively affects people's health.

However, there is evidence that refutes this viewpoint. For example, recent US data show that regions with a higher proportion of rural populations have been hit harder. A.S. Puzanov and I.N. Alov (2020), based on a review of international publications, explain the absence of a direct relationship between population density and the spread of infection by the fact that, in developed countries, densely populated regions with a high level of prosperity, education of residents, and better access to broadband Internet have greater potential for social distancing and teleworking, which makes it possible to more successfully counter the spread of infection.

The environment, primarily, air quality, has a significant impact on morbidity (infection and lethality). Air pollution levels can affect the incidence of
COVID-19 in several ways. Among them, the most significant are the higher susceptibility to lung disease in regions with high levels of air pollution with particulate matter, as well as the possibility of long-distance viral transmission via these particles. Moreover, the results of some studies (Accarino et al., 2020; Azzolina et al., 2020; Becchetti et al., 2020; Perone, 2021) suggest a causal relationship between air pollution and the effects of infection.

Resistance to the pandemic. Up to early 2021, "nonpharmaceutical interventions" were the main means of countering the spread of infection. Social distancing and stopping or limiting contact-related activity (lockdowns) remain the main ways of combating the spread of infection. Most countries have adopted various restrictive measures, but it is important not only to legislate norms and rules, but also to comply with them.

The reaction of people to restrictions and the need to follow them over, as it turned out, a long period is associated with many intertwining circumstances. Among them, not only economic losses (e.g., loss of livelihoods) are important, but also an acute change in everyday life as a result of forced isolation and breakdown of social ties, accompanied by increased anxiety, fear, and depression. Coerced social distancing triggers resistance, as evidenced by massive fines for violations, as well as abrogation of the severest restrictions (in particular, the rapid repeal of electronic passes in several Russian regions).

Compliance with constraints is not easy to assess directly. Whereas people's movements can be tracked (to some extent) using data from mobile devices, ${ }^{5}$ violations of compliance with social distancing, as well as sanitary standards and the use of personal protective equipment, are much more difficult to assess. An indirect characteristic may be the number of penalties imposed for violation of restrictions. At the end of November 2020, Russia faced the administrative responsibility of penalities for violating pandemicrelated restrictions, more than $1.1 \mathrm{mln}$ people. ${ }^{6}$

Maloney and Taskin (2020) show that the decline in mobility in developed countries is largely voluntary, dependent on awareness, fear, or social responsibility and occurs independently of the demands of government agencies; i.e., it reflects more deliberate and informed behavior rather than a reaction to repressive measures. However, for the poorest countries, such an effect did not appear, which is interpreted as forced refusal to comply with mobility restrictions due to lack of livelihood.

\footnotetext{
${ }^{5}$ People's mobility statistics are collected by Google based on data from users who have turned on the location history function in their Google account on their mobile devices, and the company emphasizes its limitations. Yandex also publishes a self-isolation index but does not disclose how it is generated.

${ }^{6} \mathrm{https}: / /$ www.rbc.ru/society/28/11/2020/5fc1e2579a794715d3bb8187.
} 
We believe that in the long term, compliance with the restrictions is more related to the social capital accumulated in a regional or local community. Social capital is viewed as a set of norms, values, and interactions adopted in a community that promote cooperation within or between groups and ensure the organization of collective actions to achieve social well-being (Grootaert, 2004; Kosarev et al., 2019; Polishchuk and Menyashev, 2011). Social capital includes trust and solidarity, collective action and cooperation, civic responsibility, social cohesion, and other categories.

We assume that in communities with a higher level of social capital, the degree of compliance with restrictive requirements will be higher. This will have a positive impact on reducing the risk of infection. There are studies that support our hypothesis ${ }^{7}$ according to which there is a high coronavirus mortality rate in countries where the level of trust in the government is low. Trust in government helps people overcome their pent-up "restriction fatigue" and continue to comply with them. During the first wave of the pandemic, trust in government increased in many countries; trust in regional and local authorities increased more often.

Measuring social capital is a difficult task. While there are several common indicators for the national level, there are very few empirical tools for assessing social capital for Russian regions. Scientists use various indicators that indirectly reflect the level of social capital. ${ }^{8}$ We used data on voter turnout as an indicator of civic responsibility, cohesion, and trust in the authorities (note that this is an indicator used in international assessments of social capital (Grootaert, 2004)).

\section{MATERIALS AND METHODS}

To check the relationship of the above-mentioned regional characteristics with the spread of COVID-19, an empirical analysis of data was carried out for 85 federal subjects. For the calculations, we used data from the Federal State Statistics Service for 2019 and 2020, ${ }^{9}$ data from the Operational Headquarters for COVID-19 in Russia (as of September 22, 2020 and

\footnotetext{
${ }^{7}$ World Bank. COVID-19 i chelovecheskii kapital. Doklad ob ekonomike regiona Evropy i Tsentralnoi Azii, osen 2020 goda (COVID-19 and Human Capital Europe and Central Asia. Economic Update. Office of the Chief Economist. Fall 2020), Washington, D.C.: World Bank. doi: 10.1596/978-1-4648-1643-7; OECD Policy Responses to Coronavirus (COVID-19). The territorial impact of COVID-19: Managing the crisis across levels of government. Updated 10 November 2020. http://www. oecd.org/coronavirus/policy-responses/the-territorial-impactof-covid-19-managing-the-crisis-across-levels-of-gavernmentd3e314e1/. Accessed April 10, 2021.

${ }^{8}$ S.P. Zemtsov and V.L. Baburin (2020a, 2020b) used the crime rate and informal employment as an inverse indicator of community members' trust in each other.

9 https://gks.ru/bgd/reg1/b20_14p/Main.htm.
}

February 13, 2021), ${ }^{10}$ data of the Central Election Commission on voter turnout for elections. ${ }^{11}$

The choice of the time period is related to the following considerations:

(1) Greater data validity. At the onset of the pandemic, there were opinions that there was a significant underestimation of the incidence of morbidity and mortality due to limited testing capabilities and discrepancies in the establishment of causes of death. The second wave was accompanied by large-scale testing and greater confidence in the causes of deaths.

(2) A reduction in the dependence of the dynamics of infections on random events. A significant increase in the number of people infected during the second wave reduced the importance of random events, in particular the impact of outbreaks and superspreading.

(3) Final consideration. The observation period from the beginning of the second wave to mass vaccination demonstrates regional characteristics in the absence of specific medications for prophylaxis and treatment. Later, the effectiveness of nonpharmaceutical actions should gradually give way to vaccination effectiveness and herd immunity. We assume that in the current conditions of persisting uncertainty, the characteristics of vulnerability and resistance of regions are of independent value, and it is especially important to understand them in the face of unpredictable global threats.

In this study, models were considered where the number of patients with COVID-19 in a federal subject and the number of COVID-related in a federal subject were the dependent variables. The indicators presented in Table 1

To assess the influence of regional factors on morbidity and mortality from coronavirus infection, regression analysis was applied (ordinary least squares, OLS). The final regression equation is:

$$
\begin{gathered}
\ln (\text { Covid })=\alpha_{0}+\alpha_{1} \times \text { Density }+\alpha_{2} \times \ln (\text { GRP }) \\
+\alpha_{3} \times \text { Education }+\alpha_{4} \times \text { Election }+\alpha_{5} \times \ln (\text { Pollution }) \\
+\alpha_{6} \times \ln (\text { Life })+\varepsilon,
\end{gathered}
$$

where Covid is an indicator characterizing the coronavirus morbidity and mortality in Russian regions (in one specification of the model, we used the number of COVID patients in a region, people, as a dependent variable; in the other, the number of COVID deaths in a region, people); Density, population density, peo$\mathrm{ple} / \mathrm{km}^{2} ; G R P$, gross regional product per capita, RUB $\mathrm{mln}$; Education, share of employed people aged 25-64 with higher education in total employed population of corresponding age group, \%; Election, turnout at the elections on September 13, 2020, \%; Pollution, atmospheric pollutant emissions, thous. t; Life, life expectancy, years.

\footnotetext{
${ }^{10}$ https://стопкоронавирус.pф/information/.

${ }^{11}$ https://cikrf...ru/analog/ediny-den-golosovaniya-2020/kategorii-viborov /.
} 
Table 1. Explanatory variables of model

\begin{tabular}{|c|c|}
\hline Regional factor & Indicator \\
\hline $\begin{array}{l}\text { Economic charac- } \\
\text { teristics }\end{array}$ & $\begin{array}{l}\text { Gross regional product per capita. } \\
\text { Share of employed population aged } \\
25-64 \text { with higher education in total } \\
\text { employed population of correspond- } \\
\text { ing age group. }\end{array}$ \\
\hline $\begin{array}{l}\text { Settlement struc- } \\
\text { ture }\end{array}$ & $\begin{array}{l}\text { Population density. } \\
\text { Presence of million-plus city. }\end{array}$ \\
\hline Economy structure & $\begin{array}{l}\text { Share of rural population in total } \\
\text { population. } \\
\text { Number of essential companies. }\end{array}$ \\
\hline Health capital & $\begin{array}{l}\text { Life expectancy. } \\
\text { Morbidity per } 1000 \text { people. } \\
\text { Population per hospital bed. }\end{array}$ \\
\hline Social capital & $\begin{array}{l}\text { Election turnout on September } 13 \text {, } \\
2020, * \%\end{array}$ \\
\hline Environment & Atmospheric pollutant emissions. \\
\hline
\end{tabular}

* For Moscow, we used voter turnout data for the 2018 Moscow mayoral elections; for St. Petersburg, on the 2019 gubernatorial election turnout; for the Kabardino-Balkar Republic, 2019 parliamentary election turnout.

Tables 2 and 3 present the econometric modeling results. The specification of the model with respect to the incidence of COVID-19 with the greatest significance and resistance (significant both for the data as of September 22, 2020 and data as of February 13, 2021) has such factors as population density, GRP per capita, atmospheric pollutant emissions, and life expectancy. In the specification model with regard to mortality from COVID-19, such factors as population density, GRP per capita, emissions of pollutants into the atmosphere and life expectancy are also the most significant.

It can be concluded that these factors to a greater extent affect both the incidence of COVID-19 and mortality from this infection in Russian regions, while their influence was noted both at the beginning and end of the observation period for the second coronavirus wave in the Russian Federation. Such factors as the proportion of employed people with higher education and electoral turnout have a greater influence on morbidity than mortality.

\section{RESULTS}

We assessed the dependences of a number of characteristics of regions on their coronavirus infection and mortality levels. The study included factors whose influence has already been substantiated in foreign and domestic studies, as well as new characteristics concerning social capital of regions. Some of the identified characteristics are ambiguous related to the spread of infection and severity of its consequences for the population. Thus, the demographic characteristics of the region, agglomeration effects, and structure of the economy, depending on specific conditions, can act in different ways.

The vulnerability of a region significantly depends on population density, air quality, the proportion of elderly people, and, unexpectedly, the level of education of the population.

We consider the revealed strong and significant influence of air quality on pollution and even stronger influence on mortality to be an important result.

The spread of infection depends on health capital: people less burdened by morbidity are better protected from and less likely to spread infection. Longer life expectancy entails an increased number of older people most vulnerable to disease.

We have included several statistical characteristics of health capital: overall morbidity, life expectancy, and number of hospital beds as a measure of the availability of health system resources. Only the hypothesis that the incidence is higher in regions with an older population was confirmed.

Table 2. Influence of regional factors on incidence of COVID-19 in federal subjects

\begin{tabular}{l|c|c}
\hline \multirow{2}{*}{ Factor } & \multicolumn{2}{c}{ Coefficient $(p$-value $)$} \\
\cline { 2 - 3 } & September 22, 2020 & February 13, 2021 \\
\hline Population density & $0.390(0.002)^{* * *}$ & $0.568(0.000)^{* * *}$ \\
GRP per capita & $-0.373(0.000)^{* * *}$ & $-0.410(0.000)^{* * *}$ \\
Share of employed with higher education & $4.536(0.007)^{* * *}$ & $2.689(0.048)^{* *}$ \\
Voter turnout & $-0.929(0.061)^{*}$ & $-1.412(0.001)^{* * *}$ \\
Atmospheric pollutant emissions & $0.412(0.000)^{* * *}$ & $0.344(0.000)^{* * *}$ \\
Life expectancy & $8.931(0.000)^{* * *}$ & $6.778(0.002)^{* * *}$ \\
F-statistic $(p$-value) & $20.76(0.000)$ & $30.75(0.000)$ \\
$\mathrm{R}^{2}\left(\mathrm{R}^{2}\right.$ corrected $)$ & $0.62(0.59)$ & $0.70(0.68)$ \\
\hline
\end{tabular}

***Significant at $p>0.01,{ }^{* *}$ significant at $p>0.05, *$ significant at $p>0.1$. 
Table 3. Influence of regional factors on mortality from COVID-19 in federal subjects

\begin{tabular}{l|c|c}
\hline \multirow{2}{*}{ Factor } & \multicolumn{2}{|c}{ Coefficient $(p$-value $)$} \\
\cline { 2 - 3 } & September 22, 2020 & February 13, 2021 \\
\hline Population density & $0.642(0.000)^{* *}$ & $0.733(0.000)^{* *}$ \\
GRP per capita & $-0.646(0.000)^{* *}$ & $-0.652(0.000)^{* *}$ \\
Share of employed with higher education & $4.260(0.078)^{*}$ & $-1.162(0.074)^{*}$ \\
Voter turnout & $-1.295(0.074)^{*}$ & $0.485(0.000)^{* *}$ \\
Atmospheric pollutant emissions & $0.450(0.000)^{* *}$ & $10.432(0.002)^{* *}$ \\
Life expectancy & $11.837(0.002)^{* *}$ & $25.86(0.000)$ \\
F-statistic $(p$-value $)$ & $17.16(0.000)$ & $0.62(0.60)$ \\
$\mathrm{R}^{2}\left(\mathrm{R}^{2}\right.$ corrected) & $0.57(0.54)$ & \\
\hline
\end{tabular}

** Significant at $p>0.01,{ }^{*}$ significant at $p>0.1$.

A number of characteristics used in our calculations were statistically insignificant. These are indicators of the structure of a region's economy (the share of rural population and number of essential businesses), indicators related to the capabilities of the healthcare system (availability of hospital beds), the health of the population (morbidity), and the presence of a million-plus city in a region.

Regions with a higher share of rural population have lower population density and fewer contacts, but older population and less access to health care resources overall. The share of rural population in Russian regions was statistically insignificant, which differs from the data for the United States, where the second wave of the pandemic was especially pronounced in rural regions.

Essential businesses are large enterprises with a large number of employees that did not stop operating during the pandemic. Calculations have shown that the presence of such enterprises in a region does not affect the spread of infection, which can be explained by the action of multidirectional factors. On the one hand, the likelihood of increased contacts and reduced social distancing stimulates the spread of infection, but on the other hand, many large enterprises have taken extraordinary measures to improve the safety of workplace interactions (testing, protective equipment, distancing, etc.), which works to counter infection.

A higher level of education of the population is positively and significantly associated with coronavirus infection, which turned out to be an unexpected result. We hypothesize that there may be various combinations of behavioral, settlement, and occupational characteristics that might explain this result. In particular, the more educated part of the population is concentrated in large cities, where the population density and frequency of contacts are higher. This part of the population may be more professionally involved in spheres of activity with a high threat of infection: health care and education. In addition, educated peo- ple may be more receptive to new information about expanded testing and the development of treatment protocols, which may reduce fear and anxiety and increase mobility and contacts. In particular, such a variant of the influence of an increase in the number of tests performed on compliance with antiepidemic restrictions is presented in (Acemoglu et al., 2020).

\section{CONCLUSIONS}

The high differentiation of Russian regions was also reflected in the scale of coronavirus infection. Based on the analysis of vulnerability factors and regional resistance factors, we demonstrated the importance of several regional characteristics associated with the spread of infection.

The wealth of a region and social capital of its population became factors of resistance to infection. Residents of wealthier Russian regions are less exposed to infection. The most vulnerable are those living in poorer regions, regions with high population densities, poorer environmental quality and older populations.

We believe that an important result is the identification of the role of social capital in resisting a pandemic. Social capital is significant, which is evident in our calculations: lower infection and mortality levels are associated with higher-quality social capital.

The development of prevention and treatment methods, as well as the transition to mass vaccination, can provide a qualitative breakthrough in combating the pandemic. Nevertheless, the core characteristics of regions are robust, and it is important to consider them when forming regional policy responses to the spread of COVID-19 and other infectious diseases in the future.

\section{FUNDING}

The study was supported by the Russian Foundation for Basic Research (project no. 19-010-00731 "Comprehensive Analysis of the Heterogeneity of Russian Regions and 
Assessment of Its Impact on Socioeconomic Development").

\section{CONFLICT OF INTEREST}

The authors declare they have no conflict of interest.

\section{REFERENCES}

Accarino, G., Lorenzetti, S., and Aloisio, G., Assessing correlations between short-term exposure to atmospheric pollutants and COVID-19 spread in all Italian territorial areas, Environ. Pollut., 2021, vol. 268, art. ID 115714.

https://doi.org/10.1016/j.envpol.2020.115714

Acemoglu, D., Makhdoumi, A., Malekian, A., and Ozdaglar, A., Testing, Voluntary Social Distancing and the Spread of an Infection: NBER Working Paper No. 27483, Cambridge, MA: Natl. Bur. Econ. Res., 2020 .

Azzolina, D., Lorenzoni, G., Silvestri, L., Prosepe, I., Berchialla, P., AND Gregori, D., Regional differences in mortality rates during the COVID-19 epidemic in Italy, Disaster Med. Publ. Health Preparedness, 2020, pp. 1-7. https://doi.org/10.1017/dmp.2020.486.

https://www.cambridge.org/core/journals/disastermedicine-and-public-health-preparedness/article/regional-differen-ces-in-mortality-rates-during-thecovid19-epide/AB38FAA500F7C916ED5D144AE2D70368. Accessed April 10, 2021.

Bailey, D., Clark, J., Colombelli, A., Corradini, C., et al., Regions in a time of pandemic, Reg. Stud., 2020, vol. 54, no. 9, pp. 1163-1174. Accessed January 12, 2021. https://doi.org/10.1080/00343404.2020.1798611

Becchetti, L., Beccari, G., Conzo, G., Conzo, P., De Santis, D., and Salustri, F., Air quality and COVID-19 adverse outcomes: Divergent views and experimental findings, Environ. Res., 2021, vol. 193, no. 4.

Europe and Central Asia Economic Update, Fall 2020: COVID-19 and Human Capital, Washington, DC: World Bank, 2020.

https://doi.org/10.1596/978-1-4648-1643-7

Grootaert, G., Narayan, D., Nyhan Jones, V., and Woolcock, M., Measuring Social Capital: An Integrated Questionnaire: World Bank Working Paper No. 18, Washington, DC: World Bank, 2004. https://openknowledge.worldbank.org/handle/10986/15033. Accessed April 1, 2021.

Hallas, L., Hatibie, A., Majumdar, S., Pyarali, M., and Hale, T., Variation in US States' Responses to COVID-19, Version 2.0, Oxford: Blavatnik Sch. Gov., 2020. http://www.bsg.ox.ac.uk/covidtracker. Accessed April 10, 2021.
Kalabikhina, I. and Panin, A., Spatial choreography of the coronavirus, Popul. Econ., 2020, vol. 4, no. 2, pp. 123152.

Kapitsinis, N., The underlying factors of the COVID-19 spatially uneven spread: Initial evidence from regions in nine EU countries, Reg. Sci. Policy Pract., 2020, vol. 12, no. 6 , pp. $1027-1045$.

https://doi.org/10.1111/rsp3.12340

Kolomak, E.A., Uneven spatial development in Russia: explanations of new economic geography, Vopr. Ekon., 2013, no. 2, pp. 132-150.

Kosarev, V., Pavlov, P., and Kaukin, A., Social capital as a factor of economic growth in the regions of Russia, Ekon. Polit., 2019, no. 5, pp. 124-149.

Maloney, W. and Taskin, T., Determinants of Social Distancing and Economic Activity during COVID-19: A Global View: Policy Research Working Paper No. 9242, Washington, DC: World Bank, 2020.

OECD Policy Responses to Coronavirus (COVID-19), The territorial impact of COVID-19: Managing the crisis across levels of government, 2020. http://www.oecd.org/coronavirus/policy-responses/ the-territorial-impact-of-covid-19-managing-the-crisis-across-levels-of-gavernment-d3e314e1/. Accessed April 10, 2021.

Perone, G., The determinants of COVID-19 case fatality rate in the Italian regions and provinces: an analysis of environmental, demographic, and healthcare factors, Sci. Total Environ, 2021, vol. 755, p. 142523.

Polishchuk, L.I. and Menyashev, R.Sh., The economic importance of social capital, Vopr. Ekon., 2011, no. 12, pp. 46-65.

Ponomarev, Yu. and Radchenko, D., The real boundaries of metropolitan areas and the distribution of coronavirus infection, Monit. Ekon. Situatsii Ross., 2020, no. 9 (111), pp. 39-47.

Puzanov, A.S. and Alov, I.N., The spread of coronavirus infection in a megalopolis: is there a relation with the parameters of population density and the state of the urban environment? 2020. http://www.urbaneconomics.ru/sites/default/files/moskva_covid_slaydy_3_puz anov_alov.pdf. Accessed April 3, 2021.

Woods, M., COVID-19, territorial inequalities and spatial justice-part one, 2020. http://imajine-project.eu/2020/05/13/covid-19-territorial-inequalitiesand-spatial-justice-part-one/. Accessed April 12, 2021.

Zemtsov, S.P. and Baburin, V.L., COVID-19: spatial dynamics and diffusion factors across Russian regions, Reg. Res. Russ., 2020a, vol. 10, no. 3, pp. 273-290. Accessed April 10, 2021. https://doi.org/10.1134/S2079970520030156

Zemtsov, S.P. and Baburin, V.L., Risks of morbidity and mortality during the COVID-19 pandemic in Russian regions, Popul. Econ., 2020b, vol. 4, no. 2, pp. 158-181. 